\title{
Exploring host and geographical shifts in transmission of haemosporidians in a Palaearctic passerine wintering in India
}

\author{
Farah Ishtiaq ${ }^{1}$
}

Received: 18 October 2016/Revised: 14 February 2017/Accepted: 27 February 2017/Published online: 9 March 2017

(C) The Author(s) 2017. This article is published with open access at Springerlink.com

\begin{abstract}
This is the first molecular study of avian haemosporidia diversity in wintering populations of the Blyth's Reed Warbler (Acrocephalus dumetorum) in India that explores the extent of host and geographical shifts in transmission areas. In 156 birds, six Haemoproteus lineages (37.8\%; 95\% CI $30.41-45.82 \%)$ and one Plasmodium lineage $(1.9 \%$; $95 \%$ CI 0.053-5.6\%) were recovered. Of these, two Haemoproteus lineages (ACDUM1 and ACDUM5) were detected in resident Himalayan birds, albeit in low frequency with absence of gametocytes in the blood suggesting no transmission from breeding to wintering quarters. In addition, there was no host sharing of local parasite lineages with the wintering populations.
\end{abstract}

Keywords Acrocephalus dumetorum · Haemoproteus . India $\cdot$ Plasmodium $\cdot$ Palaearctic $\cdot$ PCR

\section{Zusammenfassung}

Exploring host and geographical shifts in transmission of haemosporidians in a Palaearctic passerine wintering in India

This is the first molecular study of avian haemosporidia diversity in wintering populations of the Blyth's Reed

Communicated by F. Bairlein.

Electronic supplementary material The online version of this article (doi:10.1007/s10336-017-1444-9) contains supplementary material, which is available to authorized users.

Farah Ishtiaq

Ishtiaq.farah@gmail.com

1 Centre for Ecological Sciences, Indian Institute of Science, Bangalore 560012, India
Warbler (Acrocephalus dumetorum) in India that explores the extent of host and geographical shifts in transmission areas. In 156 birds, six Haemoproteus lineages (37.8\%; 95\% CI 30.41-45.82\%) and one Plasmodium lineage (1.9\%; 95\% CI $0.053-5.6 \%$ ) were recovered. Of these, two Haemoproteus lineages (ACDUM1 and ACDUM5) were detected in resident Himalayan birds, albeit in low frequency with absence of gametocytes in the blood suggesting no transmission from breeding to wintering quarters. In addition, there was no host sharing of local parasite lineages with the wintering populations.

\section{Introduction}

Blood parasite transmission in the wintering grounds and cross-species infections between migratory and resident birds is considered a cost of migration (Waldenström et al. 2002).

Understanding how parasites disperse between hosts populations is important to predict risk of emerging infectious diseases. The role of migratory birds as bridges in transmission areas has been widely documented, although the research is largely biased towards the Palaearctic-African bird migratory system (e.g., Hellgren et al. 2007). In the Central Asian Flyway, India is a staging and wintering ground for many European passerines; however, we lack information on the transmission or exchange in parasites through migrant avian hosts.

Avian malaria (Plasmodium spp.) and other haemosporidians (Haemoproteus and Leucocytozoon spp., Phylum Apicomplexa, order Haemosporida) are a diverse group of vector-borne blood parasites that have cosmopolitan distributions (Atkinson and van Riper 1991; 
Valkiūnas 2005). Plasmodium is mainly transmitted by culicine mosquitoes while biting midges (Ceratopogonids) and black flies (simulids) are responsible for transmission of Haemoproteus and Leucocytozoon, respectively.

The Blyth's Reed Warbler (Acrocephalus dumetorum) (hereafter BRW) is a Palaearctic passerine that breeds in Eastern Europe, East to Central Russia, South to North Afghanistan and winters exclusively within the Indian subcontinent south of the Himalayas, except for Pakistan and northwest India where it is only a passage migrant with short duration of occurrence during migration (Fig. 1; Ali and Ripley 1973). The BRW occurs in sympatry in breeding and wintering range with many Palaearctic passerines that winter in South Asia. However, the Paddyfield Warbler (Acrocephalus agricola) and Common Rosefinch (Carpodacus erythrinus) have been the only species studied extensively for avian haemosporidians in the breeding range (Zehtindjiev et al. 2009; Synek et al. 2013).

Here, I present results from the first molecular-based study that investigates the prevalence and diversity of haemosporidians in a Palaearctic passerine wintering over a wide geographical area in India. Specifically, I explore the degree to which BRW can form an effective bridge for blood parasites between wintering and breeding grounds, and whether parasites exhibit host and geographical shifts in transmission areas.

\section{Methods}

\section{Study sites, sample collection and blood smear preparation}

The wintering populations of the BRW were sampled in northern and southern India. In northern India, the BRW occurs as a passage migrant in Uttarakhand (UK) with two waves of arrival from April-May and October-November. In UK, bird sampling was conducted in the foothills of the Himalayas in Dehradun [DUN, $30.17409^{\circ} \mathrm{N}, 77.582535^{\circ} \mathrm{E}$; $640 \mathrm{~m}$ above sea level (a.s.l.)] in April-May $(n=35)$, September-October in 2009-2010 $(n=13)$ and AprilMay in 2014-2016 $(n=25)$. The other two UK sites: Mandal [MAN, $30.44685^{\circ} \mathrm{N}, 79.27328^{\circ} \mathrm{E} ; 1800 \mathrm{~m}$ a.s.l., $n=4$ ] and Anusuya [ANS, $30.47888^{\circ} \mathrm{N}, 79.28503^{\circ} \mathrm{E}$; $2000 \mathrm{~m}$ a.s.l., $n=7$ ] were sampled in April-May in 2014-2016. The BRW is the most common wintering warbler in southern India where sampling was conducted

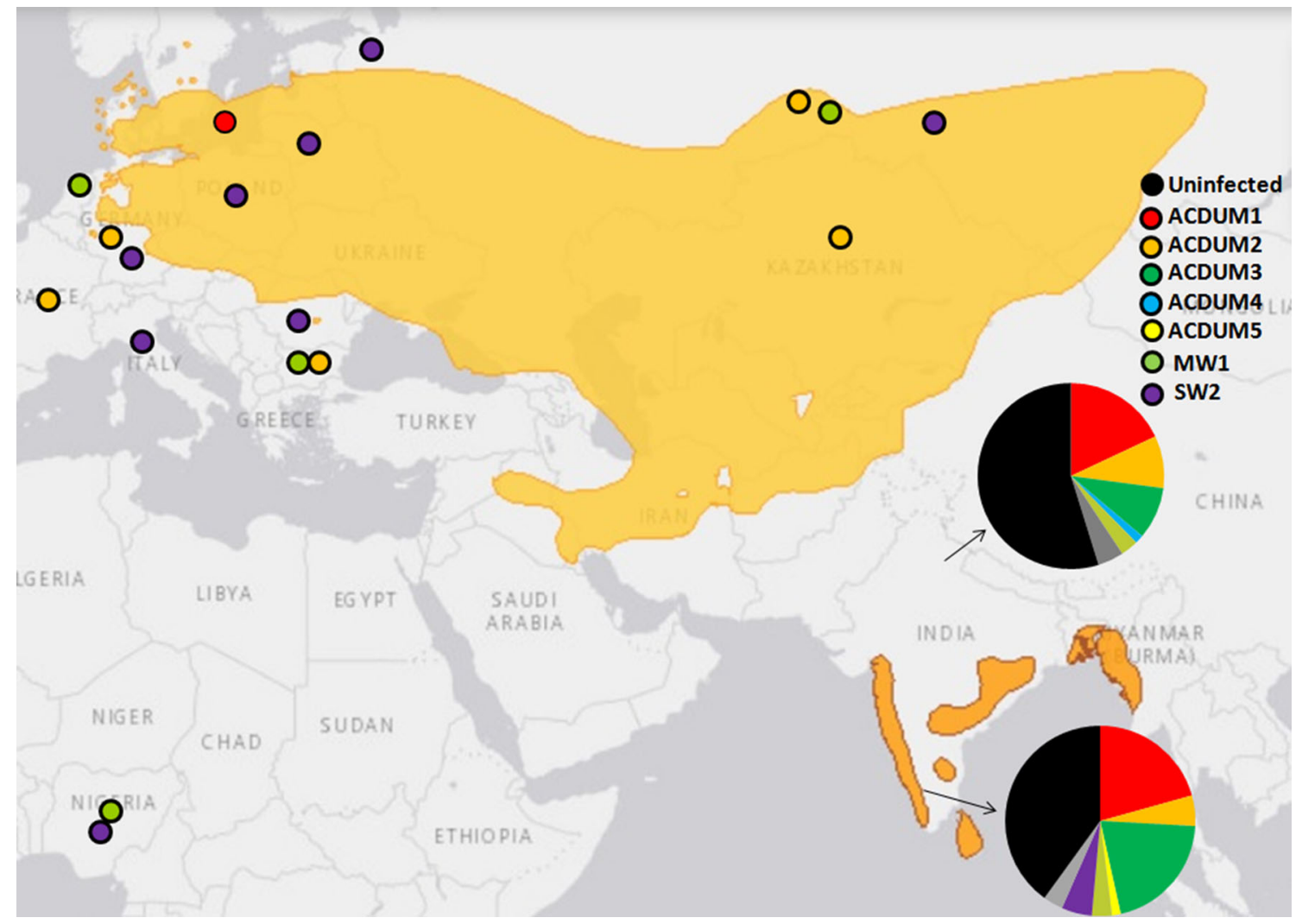

Fig. 1 Blyth's Reed Warbler distribution map with breeding (light orange) and wintering (dark orange) range. Pie graphs indicate prevalence of Haemoproteus spp. and Plasmodium spp. lineages at sampled states in India. Colour dots represent lineages found in Europe and Africa. (map is modified from BirdLife International) 
from October-March in 2014-2015 in Bangalore, Karnataka [BNG, $13.320161^{\circ} \mathrm{N}, 77.381302^{\circ} \mathrm{E} ; 900 \mathrm{~m}$ a.s.l. $n=72$; Fig. 1).

At each location, 6-12 mist nets were set up in high bird activity locations, often along forest edges, footpaths, or offroad nature trails. Mist nets were 38- mm gauge mesh, $2.6 \mathrm{~m}$ tall, and 6, 9, or $12 \mathrm{~m}$ long. Birds were sampled birds between 0540 and 1230 and nets were checked every 5-10 min. Each bird caught was identified using Rasmussen and Anderton (2005); ringed and captured individuals were released at the site after processing. Birds were not aged as many BRW were in heavy moult (see Gaston 1976).

In total, $156 \mathrm{BRW}$ were captured and $20-40 \mu \mathrm{L}$ of bird blood was sampled from the sub-brachial wing vein (never exceeding $1 \%$ of the individual's body weight). All samples were stored in SET Buffer $(20-40 \mu \mathrm{L}$ in $500 \mu \mathrm{L}$ buffer $0.15 \mathrm{M} \mathrm{NaCl}, 0.05 \mathrm{M}$ Tris, 0.001 M EDTA, pH 8.0) at room temperature and subsequently transferred to $-20^{\circ} \mathrm{C}$. From 2014 to 2016, thin blood smears from 78 birds were prepared on glass slides and then air-dried, fixed in $100 \%$ methanol and stained with Giemsa.

\section{Molecular, morphological and phylogenetic analyses}

The presence of Plasmodium, Haemoproteus and Leucocytozoon was assessed using parasite-specific primers designed to amplify partial fragments of the cytochrome $b$ (cyt $b$ ) gene (see supplementary material, S1). Molecular sexing of the birds was done by PCR with the primers 0057 $\mathrm{F}$ and $002 \mathrm{R}$ amplifying introns of the CHD1Z/W gene (Round et al. 2007). Blood smears were examined for the presence of haemosporidians and gametocytes following Godfrey et al. (1987). To explore evolutionary relationships, a model-based approach was used following phylogenetic reconstruction using the maximum likelihood analysis on the sequences isolated from the BRW in India as well as avian haemosporidian sequences (34 Haemoproteus and 21 Plasmodium) found in Acrocephalus warblers in Europe and central Asia as per the MalAvi database (Bensch et al. 2009). GenBank accession number are KY695225-KY695231.

\section{Statistical analysis}

\section{Parasite prevalence}

Using PCR-based results, for unbiased prevalence estimates, I calculated prevalence of haemosporidians with $95 \%$ confidence intervals $(95 \% \mathrm{CI})$ using the Sterne exact method (Reiczigel 2003) in Quantitative Parasitology, version 3.0 (Rózsa et al. 2000).

To assess variation in prevalence of common lineages $(n \geq 5)$ in birds sampled by gender and location (passage migration and wintering population), a generalised linear model (GLM) was used with the number of birds infected and number uninfected as the binomial response variable and location as the categorical explanatory variable. Data for two sampling periods (2009-2010 and 2014-2016) in UK were analysed together as there was not enough statistical power for temporal analysis. Analyses were conducted in $\mathrm{R}$ v. 3.0.1( $\mathrm{R}$ Core Team 2012).

\section{Estimation of parasite lineage richness}

To estimate success in sampling all available parasite lineages in wintering BRW populations, I calculated a rarefaction (species-area) curve and estimated true lineage richness with classic Chao2 estimations (Colwell 2013). I used ESTIMATES version 9.0 (Colwell 2013) to construct linked rarefaction and extrapolation curves. Parasite richness (Chao2) estimates were considered to be significantly different if $95 \%$ confidence intervals (CIs) did not overlap.

\section{Results}

\section{Parasite prevalence}

Avian haemosporidian infections were found in 64 out of 156 (41.02\%; 95\% CI 33.3-49\%) individuals across all BRW populations. Of the positive samples, 37.8\% $(95 \% \mathrm{CI}$ $30.41-45.82 \%)$ were Haemoproteus spp. and $1.9 \%(95 \%$ CI 0.053-5.6\%) were Plasmodium spp. None of the samples were infected with Leucocytozoon spp. Prevalence of Haemoproteus spp. in wintering site (BNG: 60.3\%; 95\% CI 47.4-72.5\%) and in passage migration (UK) sampled in 2009 (45\%; 95\% CI 29.7-61.2\%), and 2014-2016 (38.5\%; 95\% CI 21.17-57.7\%) did not show significant difference $\left(\chi^{2}=4.23, d f=2, P=0.12\right)$. Similarly, there was no significant difference in prevalence of Haemoproteus spp. (GLM: $\chi^{2}=1.45, P=0.23$ ) by gender.

In total, 78 BRW blood smears collected, of which 75 (96\%) were in agreement with PCR with medium to high intensity Haemoproteus (98\%) and Plasmodium (1\%) infections and three were submicroscopic. All infected smears showed the presence of both male and female gametocytes.

There were six Haemoproteus lineages and one Plasmodium lineage recovered from BRW populations (Fig. 1), of which three Haemoproteus lineages, ACDUM3, ACDUM4 and ACDUM5 have not been described previously (supplementary material S1, Table S1). The Plasmodium lineage SW2 $(n=3)$ was only found in BNG. The prevalence of lineages showed no significant difference by gender ACDUM1 (GLM: $\chi^{2}=0.68, P=0.72$ ), ACDUM2 (GLM: $\chi^{2}=0.68, P=0.72$ ) and location: ACDUM1 (GLM: $\quad \chi^{2}=0.12, \quad P=0.72$ ), ACDUM3 $\quad$ (GLM: 
$\left.\chi^{2}=3.37, \quad P=0.06\right), \quad$ MW1 $\quad\left(\right.$ GLM: $\quad \chi^{2}=0.017$,

$P=0.89$ ), and ACDUM2 (GLM: $\left.\chi^{2}=0.72, P=0.39\right)$.

\section{Estimation of parasite lineage richness}

The BRW populations in passage migration (UK) and wintering (BNG) sites showed no difference in lineage richness as evidenced by overlapping Chao 2 95\% CIs (Table 1). Across the entire BRW populations, the accumulation curve reached an asymptote (Sobs $=7$, Chao $2=6.14 \pm 1.45$; supplementary material S1, Figure S1).

\section{Parasite lineage diversity, host and geographical shifts}

The parasite phylogeny included 32 Haemoproteus lineages and 20 Plasmodium lineages, of which seven lineages were found in the BRW (Fig. 2). Five Haemoproteus lineages in the BRW fall in the $H$. belopolyski clade. Of which three lineages ACDUM1, ACDUM2 and MW1 have been recovered in Acrocephalus and Hipplolais warblers in Europe, Russia and non-Acrocephalus hosts in Africa. In India, ACDUM1 was shared with a Pink-browed Rosefinch Carpodacus rodochroa and ACDUM5 was found in a Streaked Laughingthrush Trochalopteron lineatum sampled in UK. Two newly recovered Haemoproteus lineages showed $0.2 \%$ (corresponds to $1 \mathrm{bp}$ substitution) sequence divergence between ACDUM1/ACDUM4 and MW1/ACDUM3.

\section{Discussion}

The wintering populations of BRW harboured a Haemoproteus dominated parasite assemblage with absence of infectious stages in resident birds in the wintering ground.
In particular, a large proportion of Haemoproteus lineages in $H$. belopolsyki clade appears to be a complex of recently diversified $(0.2 \%$; corresponds to $1 \mathrm{bp}$ substitution) lineages within the BRW. The BRW occurs in sympatry in breeding range with Acrocephalus agricola (winter in south Asia) and Acrocephalus scirpaceus (winter in subSaharan Africa) which potentially facilitates the transfer of host-specific parasites in phylogenetically closely related species (see Cooper et al. 2012).

The lineages ACDUM2 and MW1 were shared only with Acrocephalus warblers in breeding quarters and not detected in resident birds $(\sim 3000)$ in India (Ishtiaq et al., unpublished) which suggest that transmission is restricted to Europe and Africa. The most prevalent lineage ACDUM1 differs by single base pair substitution with ACAGR2, a lineage common in the Paddyfield Warbler in Bulgaria and Russia (Zehtindjiev et al. 2009). However, based on a 351 bp cyt $b$ identical match, both lineages have been reported in three resident avian hosts in India (Ishtiaq et al. 2007; Bensch et al. 2009). In addition, two lineages, ACDUM1and ACDUM5, were detected in resident Himalayan birds, albeit in low frequency, that point towards shift in transmission areas as India or possible spill over infections (see Hellgren et al. 2009). Whilst this may be an artefact, as the PCR technique does amplify sporozoite DNA (Valkiūnas et al. 2009), a close examination of blood smears from resident Himalayan birds confirmed the absence of gametocytes in the blood as several biotic (e.g., competent vectors) and abiotic (e.g., temperature) factors are central for parasite to complete its development in a new environment. The only detected Plasmodium lineage SW2 that was previously identified as Plasmodium homonucleophilum has been found in multiple avian hosts in Europe, Central Asia, Africa and India.
Table 1 Lineage diversity estimates (Chao $2 \pm \mathrm{SD})$ across wintering populations of the Blyth's Reed Warbler in India

\begin{tabular}{|c|c|c|c|c|c|c|c|c|c|c|}
\hline \multirow[t]{2}{*}{ Site } & \multirow[t]{2}{*}{ Year } & \multirow[t]{2}{*}{$N$} & \multicolumn{3}{|c|}{ Male/female } & \multirow[t]{2}{*}{$M$} & \multirow[t]{2}{*}{$N_{\text {seq }}$} & \multirow[t]{2}{*}{ Sobs } & \multirow[t]{2}{*}{ Chao2 } & \multirow[t]{2}{*}{$95 \% \mathrm{CI}$} \\
\hline & & & $N$ & $H$ & $P$ & & & & & \\
\hline \multicolumn{11}{|c|}{ Northern India: passage migrant } \\
\hline DUN & 2009 & 48 & $33 / 15$ & $11 / 7$ & 0 & 2 & 20 & 5 & $4.11 \pm 1.29$ & $3.39-10.07$ \\
\hline DUN & 2014-2016 & 25 & $21 / 4$ & $6 / 1$ & 0 & 0 & 7 & & & \\
\hline MAN & 2016 & 4 & $3 / 1$ & $1 / 0$ & 0 & 0 & 1 & & & \\
\hline ANS & 2016 & 7 & $6 / 1$ & $2 / 1$ & 0 & 0 & 0 & & & \\
\hline Total & & 84 & $63 / 21$ & $20 / 9$ & 0 & 0 & 8 & 4 & $3.14 \pm 1.12$ & $2.49-8.08$ \\
\hline \multicolumn{11}{|c|}{ Southern India: wintering } \\
\hline $\mathrm{BNG}$ & 2014-2016 & 72 & $34 / 38$ & $15 / 15$ & $1 / 2$ & 0 & 33 & 6 & $5.21 \pm 1.18$ & $4.58-10.61$ \\
\hline Total & & 156 & & 59 & 3 & 0 & 61 & 7 & $6.31 \pm 1.98$ & $5.35-16.57$ \\
\hline
\end{tabular}

DUN, Dehradun; MAN, Mandal; ANS, Anusuya; $B N$, Bangalore; $N$, sample size of birds screened; $H$, Haemoproteus infection; $P$, Plasmodium infection; $M$, mixed infection; $N_{\text {seq }}$, number of infected samples that were sequenced to determine lineage identity; Sobs, number of lineages detected; Chao2, lineage diversity estimate \pm standard deviation; $95 \%$ CI, Chao2 95\% confidence interval 


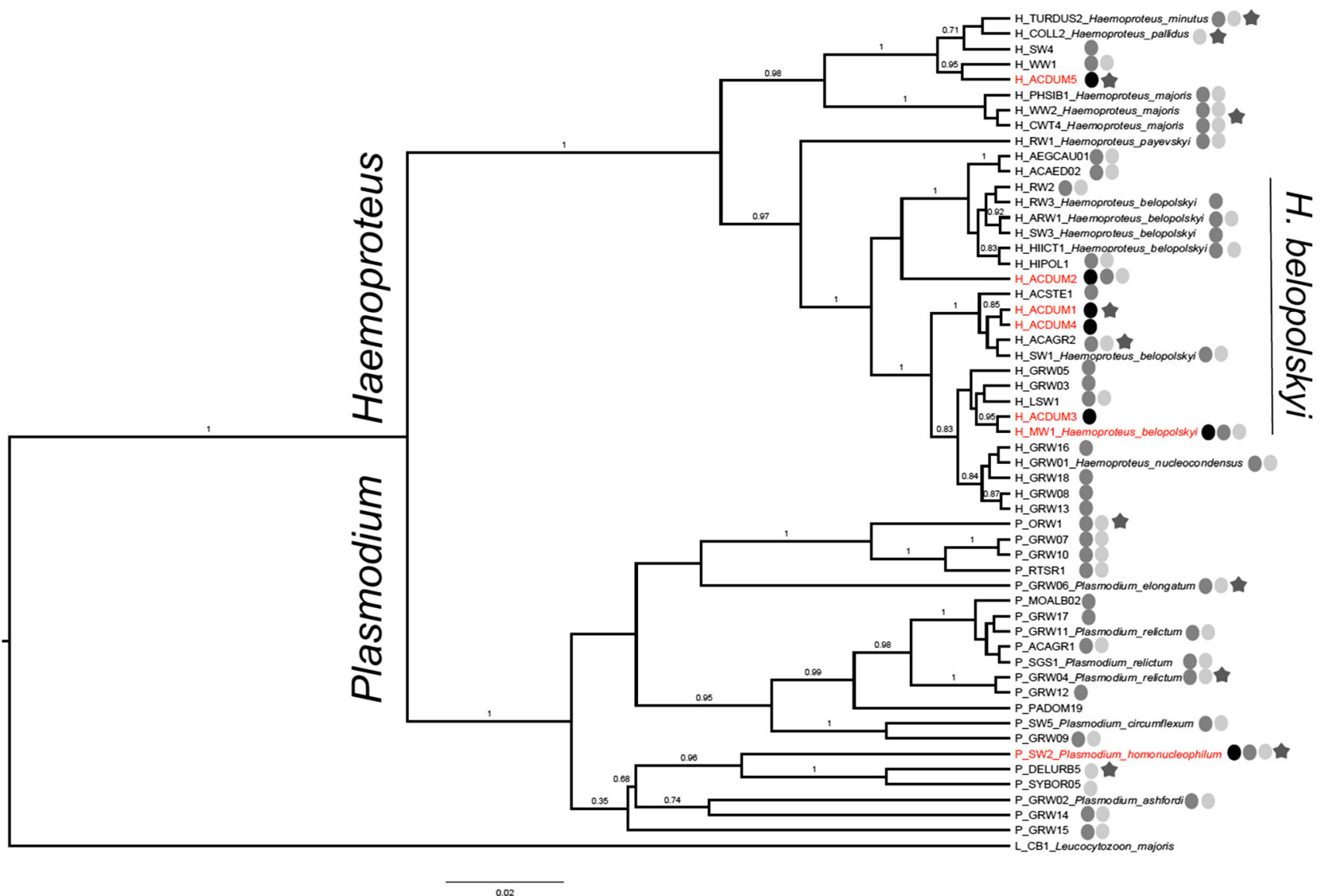

Fig. 2 Maximum clade credibility tree of Plasmodium and Haemoproteus lineages recovered from Blyths' Reed Warbler in India from based on cytochrome $b$ gene (477 bp). Posterior clade probability support values above 0.5 are shown. Lineages found in Blyth's Reed

Given the limited sample size, the lineage accumulation curve reached an asymptote, and it is worth pointing out that there were generalist and widely distributed parasites lineages (e.g., GRW4, DELURB4) found in resident birds in India but not harboured in the BRW. Future study in the breeding range will help to understand the parasite selection pressure and migration strategy of the BRW wintering in India.

Acknowledgements The study was funded by the Wellcome Trust/ DBT India Alliance (IA/I(S)/12/2/500629) and the Marie-Curie Fellowship of the European Commission under contract number MIF1CT-2006-040845. Birds were captured and sampled with ethical approval and permission from Uttarakhand and Karnataka State Forest Departments. I am grateful to the Director, Wildlife Institute of India for support and Dr. Y. V. Jhala for facilitating this research in Uttarakhand. C. Bowden, V. Palinauskas, S. Barve, M. Rao and R. Menzies helped with fieldwork and K. Narayanan helped in the lab. Two anonymous reviewers substantially improved the manuscript. The field experiments comply with the current laws of the India where the study was performed.
Warbler are in red text and indicated with black oval dot. Lineages shared with other Acrocephalus warblers are in grey dot. Lineages shared with other avian host are shown in light grey dot. Star indicates lineages shared with avian hosts in India

Open Access This article is distributed under the terms of the Creative Commons Attribution 4.0 International License (http://crea tivecommons.org/licenses/by/4.0/), which permits unrestricted use, distribution, and reproduction in any medium, provided you give appropriate credit to the original author(s) and the source, provide a link to the Creative Commons license, and indicate if changes were made.

\section{References}

Ali S, Ripley SD (1973) The handbook of the birds of India and Pakistan. Oxford University Press, Delhi

Atkinson CT, van Riper IIIC (1991) Pathogenicity and epizootiology of avian haematozoa: Plasmodium, Leucocytozoon, and Haemoproteus. In: Loye JE, Zuk M (eds) Bird-parasite interactions: ecology, evolution and behaviour. Oxford University Press, New York, pp 19-48

Bensch S, Hellgren O, Pérez-tris J (2009) MalAvi: a public database of malaria parasites and related haemosporidians in avian hosts based on mitochondrial cytochrome $b$ lineages. Mol Ecol Resour 9:1353-1358 
Colwell RK (2013) EstimateS: Statistical estimation of species richness and shared species from samples. Version 9. User's Guide and application published at: http://viceroy.eeb.uconn. edu/estimates/. Accessed 24 Jan 2017

Cooper N, Griffin R, Franz M, Omotayo M, Nunn CL (2012) Phylogenetic host specificity and understanding parasite sharing in primates. Ecol Lett 15:1370-1377

Gaston AJ (1976) The moult of Blyth's reed warbler Acrocephalus dumetorum, with notes on the moult of other Palaearctic warblers in India. Ibis 118:247-251

Godfrey RD, Fedynich AM, Pence DB (1987) Quantification of haematozoa in blood smears. J Wildl Dis 23:558-565

Hellgren O, Waldenström J, Pérez-Tris J, Szollosi E, Hasselquist D, Križanauskienė A, Ottosson U, Bensch S (2007) Detecting shifts of transmission areas in avian blood parasites-a phylogenetic approach. Mol Ecol 16:1281-1290

Hellgren O, Pérez-Tris J, Bensch S (2009) A jack-of-all-trades and still a master of some: prevalence and host range in avian malaria and related blood parasites. Ecology 90:2840-2849

Ishtiaq F, Gering E, Rappole JH, Rahmani AR, Jhala YV et al (2007) Prevalence and diversity of avian hematozoan parasites in Asia: a regional survey. J Wildl Dis 43:382-398

Rasmussen PC, Anderton JC (2005) Birds of South Asia: the ripley guide. Smithsonian Institution and Lynx Edicions, Barcelona

Reiczigel J (2003) Confidence intervals for the binomial parameter: some new considerations. Stat Med 22:611-621
Round PD, Hansson B, Pearson DJ, Kennerley PR, Bensch S (2007) Lost and found: the enigmatic large-billed reed warbler Acrocephalus orinus rediscovered after 139 years. J Avian Biol 38:133-138

Rózsa L, Reiczigel J, Majoros G (2000) Quantifying parasites in samples of hosts. J Parasitol 86:228-232

Synek P, Albrecht T, Vinkler M, Schnitzer J, Votýpka J, Munclinger P (2013) Haemosporidian parasites of a European passerine wintering in South Asia: diversity, mixed infections and effect on host condition. Parasitol Res 112:1667-1677

Valkiūnas G (2005) Avian malaria parasites and other haemosporidia. CRC Press, Boca Raton, FL, p 946

Valkiūnas G, Iezhova TA, Loiseau C, Sehgal RNM (2009) Nested cytochrome $\mathrm{B}$ polymerase chain reaction diagnostics detect sporozoites of hemosporidian parasites in peripheral blood of naturally infected birds. J Parasitol 95:1512-1515

Waldenström J, Bensch S, Kiboi S, Hasselquist D, Ottosson U (2002) Cross-species infection of blood parasites between resident and migratory songbirds in Africa. Mol Ecol 11:1545-1554

Zehtindjiev P, Ilieva M, Križanauskiene A, Oparina O, Oparin M, Bensch S (2009) Occurrence of haemosporidian parasites in the paddyfield warbler, Acrocephalus agricola (Passeriformes, Sylviidae). Acta Parasitol 54:295-300 